\title{
Endotracheal Intubations in Emergency Department: A Clinical Audit at a Tertiary Health Centre in South India
}

\author{
Linu SM ${ }^{1 *}$, Roopasree Sivam ${ }^{2}$, Nikhil Paul ${ }^{3}$, Mathen P George ${ }^{4}$, Suresh Babu ${ }^{5}$
}

Received: 21 June 2021 / Accepted: 10 July 2021 / Published online: 20 July 2021

This article is published with open access at https://journal.astes.org.al

(C) The author(s) 2021. \& Copyright (C) 2021, the Albanian Society for Trauma and Emergency Surgery

@ The Albanian Journal of Trauma and Emergency Surgery is an Open Access Journal. All articles are distributed under the terms of the Creative Commons Attribution Non-Commercial License: http://creativecommons.org/licenses/by-nc/4.0/) which permits unrestricted non-commercial use, distribution, and reproduction in any medium provided the original work is properly cited.

\begin{abstract}
Background: Endotracheal intubation in the emergency department is challenging. Hence, regular audits can help us improve our critical airway management skills. Our study aimed to evaluate the practice of endotracheal intubations performed in the emergency department.

Materials and Methods: A retrospective cross-sectional study was conducted among the patients intubated in our teaching hospital's emergency department. The study period was from November 1, 2019, to August 31, 2020. We analyzed first attempt success rates, drug use, indication, and complications.

Results: We analysed 90 endotracheal intubations, out of which 70(77.8\%) were performed by emergency physicians and 20(22.2\%) by anaesthetists. The first attempt success rate was $81.11 \%(\mathrm{n}=73)$ and had significant differences between the both departments. (p value $=0.003, \chi 2=7.48)$. More patients had medical indications compared to trauma for intubation $(\mathrm{n}=88 \mathrm{vs} \mathrm{n}=32)$ among which respiratory failure $(\mathrm{n}=25,27.78 \%)$ was the most common indication. Rapid Sequence Intubation( RSI) adherence was $82.22 \%$ $(n=74)$. Lignocaine $(n=16,19.75 \%)$, etomidate $(n=35,43.2 \%)$ and succinylcholine $(n=65,80.25 \%)$ were the commonly used drugs for premedication, induction and as relaxants respectively. 17(18.89\%) out of 90 intubation had complications. Desaturation ( $\mathrm{n}=10$, $11.11 \%)$, bradycardia $(n=1,1.11 \%)$, hypotension $(n=4,44 \%)$, dental trauma $(n=5,5.55 \%)$ and oesophageal intubation $(n=3,3.33 \%)$ were observed in our study.

Conclusion: Our study is the first from India which describes the characteristics of endotracheal intubations done in the Emergency Department along with data on RSI adherence. The first attempt success rate, indications, and complications were comparable with other studies in the literature. We recommend future prospective studies to analyze success rates between different specialties and resident doctors to improve the airway management skills in the Department
\end{abstract}

Keywords: Critical airway management, Residency training, Academic emergency department, Emergency physician, anesthetist.

\section{Introduction}

Endotracheal intubation has become the gold standard technique in airway management of critically ill patients [1]. A doctor working in the emergency department should

Original article, no submission or publication in advance or in parallel

* Corresponding author:

Dr. Linu SM, MD, DNB, Assistant Professor

$\triangle$ linu24886@gmail.com

1 Department of Emergency Medicine, Sree Gokulam Medical College and Research Foundation, Trivandrum-695607, Kerala, INDIA.

2 Department of Emergency Medicine, Government Medical College, Trivandrum, Kerala, INDIA.

3 Department of Emergency Medicine, Sree Gokulam Medical College and Research Foundation, Kerala, INDIA.

4 Department of Emergency Medicine, Sree Gokulam Medical College and Research Foundation, Kerala, INDIA.

5 Department of Anesthesiology, Sree Gokulam Medical College and Research Foundation, Kerala, INDIA. manage the airway of the critically ill patient for the first 30 minutes [2]. In this regard, endotracheal intubation is recognized as a core skill required for any doctor who manages the emergency department. The Government of India had accepted emergency medicine as a separate specialty by 2009 and started the first residency program in 2010 [3]. Because of this fact, the workforce of Emergency Departments across India comprises doctors from diverse specialties like emergency medicine, anesthesia, general medicine, and general surgery. Endotracheal intubation in the emergency department is generally performed by either an emergency physician or an anesthesiologist [4,5]. In the emergency department of our institution, the emergency physician performs intubation during the day shift (09:00 to 21:00), and the anesthetist performs during the night shift (21:00 to 09:00). Endotracheal intubation performed in the 
emergency department is often challenging. Some argue that this should be only performed by experts in the field. This is because those patients in the emergency department requiring endotracheal intubation may be restless and uncooperative. In many clinical situations, the time of the last meal of patients requiring emergency endotracheal intubation is unknown. These factors ultimately lead to an increased incidence of complications. Even though there are reports from developed countries published on endotracheal intubation in the emergency department $[1,2,6]$. Only very few published reports are available from India [7]. The data on outcomes, especially in patients with complications, are not well understood. Frequent audits of core skills like endotracheal intubation in the Emergency Department of a Teaching hospital can help understand the pitfalls and identify lacunae in airway management training. Such audits help in improving the standards of airway management training of emergency medicine residents. Our study aimed to evaluate the practice of endotracheal intubation performed in the emergency medicine department of a tertiary health centre.

\section{Materials and Methods}

The Human Research Ethics Committee of Sree Gokulam Medical College Trivandrum granted permission for the study (Number: SGMC IEC/44/571/04/2021/F).

A retrospective cross-sectional study was conducted at Sree Gokulam Medical College Trivandrum, 700 bedded teaching hospital and a tertiary health center located in Kerala, India. Patients who underwent endotracheal intubation from November 1, 2019, to August 31, 2020, in the emergency department of our hospital were included in our study. Procedures performed by post-graduate residents were excluded. The sampling method was consecutive. All patients satisfying the inclusion criteria were included in the study to minimize sampling bias.

Details of potential study patients who were intubated during the study period were perused from the records file/ using the ICD. Code. Their MRD. Numbers (Medical records department or MRD number is a unique patient identification number given to all patients during OP visit/ I.P. admission) were used to trace their case files. Data for the study variables were collected from the airway registry attached with the case files of individual patients[8]. The airway registry was filled up by the resident doctor of the emergency department after every endotracheal intubation that occurred in the Emergency Department. Study variables included indication for endotracheal intubation, drugs used, the specialty of the intubating doctor, number of attempts, pre-oxygenation mode, success rates of the first attempt, use of bougie during intubation, and complication rates. LEON (Modified LEMON ) criteria [9] was used for difficult airway assessment before intubation, and the Cormack-Lehane (CL) classification [10] of laryngoscopic view during each attempt was also recorded. Both these parameters were included as study variables.
An emergency physician who works in our Department has completed three years of a residency training program from any of the academic centers approved for the same. The emergency department in our tertiary center started its residency program accredited by The National Board of Examinations in 2019 with an annual intake of three residents.

For this study, we defined an attempt at intubation as the single passage of the laryngoscope blade beyond the lips by the intubating doctor ${ }^{8}$. RSI (Rapid Sequence Intubation) was defined as the nearly simultaneous administration of a potent sedative (induction) agent and neuromuscular blocking agent for tracheal intubation[11]. Endotracheal intubation was confirmed using five-point auscultation and post-procedure chest X-ray.

Indication for endotracheal intubation included trauma (head trauma, neck / facial trauma, chest trauma, burns/ inhalation injury, drowning, shock, traumatic cardiac arrest) and medical (respiratory failure, airway obstruction, anaphylaxis, cardiac failure, cardiac arrest, sepsis, GI bleed, seizures, stroke/ intracranial bleed, altered mental status, overdose/ ingestion).

Different drugs used during intubation are given in Table 1. The intubating doctor was either an emergency physician or an anesthetist. Pre-oxygenation modes included bag- valve- mask (BVM), non-rebreather mask (NRBM), and continuous positive airway pressure (CPAP). Complications $^{8}$ included desaturation (fall of oxygen saturation below $93 \%$ ), bradycardia (pulse rate less than 60 per minute), hypotension (defined as systolic BP below $90 \mathrm{~mm} \mathrm{Hg}$ or a reduction of more than $20 \%$ from baseline that could not be otherwise explained and requiring administration of intravenous crystalloids or inotropes), dental trauma (any damage to the teeth/gums due to laryngoscopy), airway trauma, oesophageal intubation, mainstem bronchial intubation, vomiting (occurring after the intubation procedure), laryngospasm, and cardiac arrest.

\section{Table 1. Showing different groups of drugs given to the} patients.

\begin{tabular}{|l|l|l|}
\hline Pre-medications & Relaxant & Inducing agent \\
\hline Atropine & Succinylcholine & Propofol \\
Lignocaine 20\% & Rocuronium & Etomidate \\
Fentanyl & Atracurium & Ketamine \\
Lignocaine 20\% and Fentanyl & & Fentanyl \\
Glycopyrrolate & & Midazolam \\
\hline
\end{tabular}

Statistical analysis: Study variables were also compared among doctors from emergency medicine and anaesthesiology. Chi-square testing was used to check for the association between them. $\mathrm{P}$ values less than 0.05 were considered significant. Sensitivity analysis was not performed, and there was no missing data. All the data were entered in Microsoft Excel and was analyzed using SPSS version 25 (Statistical Package for the Social Sciences, SPSS Inc., USA). 


\section{Results}

Over a ten-month study period, we evaluated 90 endotracheal intubations performed in the emergency department. Out of these, $60(67 \%)$ were male, and $30(33 \%)$ were females. The age groups of the study patients ranged from eight years to 84 years, with the majority $(n=59,65.5 \%)$ belonging to 55 years to 75 years (Figure 1). The mean age was 61.2 years with $\mathrm{SD} \pm 14.31$ and IQR 17.25. Overall, 70 (77.78\%) patients were intubated by emergency physicians, whereas anesthetists intubated $20(22.22 \%)$ patients.

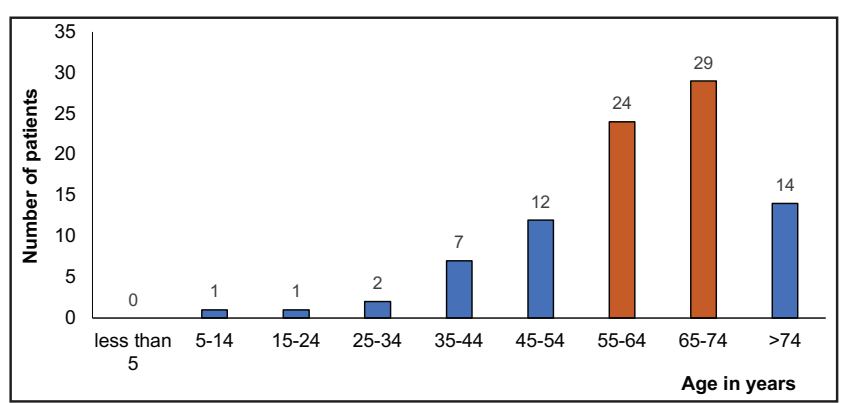

Figure 1: showing the age distribution of study patients and distribution of intubation performed among emergency physicians and anesthetists.

We classified the indications for endotracheal intubation into trauma and medical causes (Table 2). The majority of the patients $(n=77,85.55 \%)$ had only one

Table 2. showing indications (trauma and medical causes) for endotracheal intubation among the study patients

\begin{tabular}{|c|c|c|}
\hline Indication & $\begin{array}{l}\text { Number of } \\
\text { patients }(n=90)\end{array}$ & $\begin{array}{c}\text { Percentage } \\
(\%)\end{array}$ \\
\hline \multicolumn{3}{|l|}{ Trauma } \\
\hline Head injury with reduced GCS. & 16 & 17.78 \\
\hline Head injury with non-patent airway & 7 & 7.78 \\
\hline Neck/ Facial trauma & 2 & 2.22 \\
\hline Burns & 1 & 1.11 \\
\hline Chest trauma & 2 & 2.22 \\
\hline Traumatic cardiac arrest & 1 & 1.11 \\
\hline Shock & 1 & 1.11 \\
\hline \multicolumn{3}{|l|}{ Medical } \\
\hline Respiratory failure & 25 & 27.78 \\
\hline Airway obstruction & 1 & 1.11 \\
\hline Cardiac failure & 4 & 4.44 \\
\hline Sepsis & 2 & 2.22 \\
\hline GI bleed & 4 & 4.44 \\
\hline Seizures & 6 & 6.67 \\
\hline ICH/ Stroke & 21 & 23.33 \\
\hline Cardiac arrest & 8 & 8.89 \\
\hline Altered mental status & 8 & 8.89 \\
\hline Overdose/ ingestion & 01 & 1.11 \\
\hline
\end{tabular}

indication for intubation. However, eight (8.88\%) had two indications, four $(4.44 \%)$ had three indications, and one patient had five indications for intubation. Overall, emergency physicians intubated eight patients (11.4\%) with more than one indication, whereas anesthetists intubated five $(25 \%)$ patients with more than one indication. However, the differences between them were not statistically significant $(p=0.063)$. Respiratory failure $(n=25,27.78 \%)$ was the most common indication found among the study patients, followed by intracranial hemorrhage/ stroke $(n=21,23.3 \%)$. Among the patients with a history of trauma, head injury with reduced GCS $(n=17,18.8 \%)$ was the most common indication for intubation.

The preoxygenation modes were bag-valve-mask (BVM) in $65(72.22 \%)$ patients, among which $48(68.57 \%)$ were intubated by emergency physicians and the remaining $17(85 \%)$ by anesthetists, non-re-breather mask (NRBM) in $15(16.67 \%)$ in which $13(18.57 \%)$ by emergency physicians and $2(10 \%)$ by anesthetists, and continuous positive airway pressure (CPAP) in one participant (1.1\%) who was intubated by the anesthetist. Patients with indications for endotracheal intubation received premedications, induction agents, and relaxants (Table 3). Patients who had cardiac arrest either due to medical conditions or

Table 3. showing medications used and drug preferences for endotracheal intubation.

\begin{tabular}{|l|l|l|l|}
\hline Drugs & Total n(\%) & $\begin{array}{l}\text { Emergency } \\
\text { medicine n(\%) }\end{array}$ & $\begin{array}{l}\text { Anesthesia } \\
\mathrm{n}(\%)\end{array}$ \\
\hline Pre-medications & $16(19.75 \%)$ & $13(21.31 \%)$ & $3(15 \%)$ \\
\hline Lignocaine 20\% & $13(16.04 \%)$ & $5(8.19 \%)$ & $8(40 \%)$ \\
\hline Fentanyl* & $13(16.04 \%)$ & $13(21.31 \%)$ & 0 \\
\hline Lignocaine 20\%+Fentanyl & $2(2.47 \%)$ & 0 & $2(10 \%)$ \\
\hline Glycopyrrolate* & $37(45.68 \%)$ & $30(49.18 \%)$ & $7(35 \%)$ \\
\hline No drug & $32(39.51 \%)$ & $22(36.06 \%)$ & $10(50 \%)$ \\
\hline Induction agents & $7(8.64 \%)$ & $6(9.84 \%$ & $1(5 \%)$ \\
\hline Propofol & $5(6.17 \%)$ & $1(1.64 \%)$ & $4(20 \%)$ \\
\hline Ketamine & $35(43.21)$ & $32(52.46 \%)$ & $3(15 \%)$ \\
\hline Fentanyl* & $01(1.23 \%)$ & 0 & $1(5 \%)$ \\
\hline Etomidate* & $01(1.23 \%)$ & 0 & $1(5 \%)$ \\
\hline Midazolam & \multicolumn{5}{|l}{} \\
\hline No drug & $65(80.25 \%)$ & $51(83.61 \%)$ & $14(70 \%)$ \\
\hline Relaxant & $08(9.88 \%)$ & $8(13.11 \%)$ & 0 \\
\hline Succinylcholine & $01(1.23 \%)$ & 0 & $1(5 \%)$ \\
\hline Rocuronium & $7(8.64 \%)$ & $2(3.28 \%)$ & $5(25 \%)$ \\
\hline Atracurium & \multicolumn{5}{|l}{} \\
\hline No drug* & &
\end{tabular}

$\left.{ }^{*}\right)$ shows drugs that have significant differences in use among the emergency physicians and anesthetists. Fentanyl $\left(\chi^{2}=\right.$

$11.31 ; p=<0.01)$, Lignocaine $20 \%+$ Fentanyl $(\chi 2=3.619 ; p=$ $0.028)$, Glycopyrrolate $(\chi 2=2.791 ; p=0.047)$, Fentanyl $(\chi 2=$ $8.767 ; p=<0.01)$, Etomidate $(\chi 2=7.154 ; p=0.003)$, No relaxant $(\chi 2=6.46 ; p=0.005)$. 
trauma did not receive any drugs. They did not receive any form of preoxygenation. Thirty-seven patients (45.68\%) did not receive any premedications. Lignocaine $(n=16$, $19.75 \%$ ) was the most common premedication given to the patients. Except for one (1.23\%), all the remaining 80 patients received induction drugs. Propofol $(n=32,39.5 \%)$ and Etomidate $(n=35,43.2 \%)$ were the commonly used induction drugs. Among the relaxants, most $(n=65,80.24 \%)$ received succinylcholine, whereas seven $(8.64 \%)$ patients did not receive any relaxant.

To grade laryngoscopic views obtained by the intubating doctor (Figure 2). Overall, 58(64.44\%) had grade one, $20(22.22 \%)$ had grade two, nine $(10 \%)$ had grade three, and only three $(3.33 \%)$ had grade four. Seven out of $70(10 \%)$ intubation performed by emergency physicians had CL grades more than two compared to five out of $20(25 \%)$ intubations performed by anesthetists. Out of 90 endotracheal intubations performed, 26 (28.9\%) required the use of a bougie (Figure 2). Of these, 23 $(88.46 \%)$ were done by emergency physicians, and the remaining three $(11.54 \%)$ by anesthetists. There was a significant difference between the emergency physicians and anesthetists in terms of LEON criteria was used to predict the difficulty of endotracheal intubation (Figure 02). Overall, $31(38.27 \%)$ patients were expected to have difficult intubation. Of these, emergency physicians intubated $17(54.84 \%)$ patients, and the anesthetist intubated the remaining $14(45.16 \%)$ patients. We used CL classification predicted difficult intubation $(\chi 2=14.4, \mathrm{p}$ $<0.001)$ and bougie use $(\chi 2=16.32, \mathrm{p}<0.001)$.
Among the 90 endotracheal intubations performed, $74(82.22 \%)$ were rapid sequence intubations (RSI). Among these, emergency physicians performed 59(79.73\%) and the remaining $15(20.27 \%)$ by anesthetists. The differences between them were statistically significant. $(\chi 2=6.46$; $\mathrm{p}=0.0013)$. Out of the 74 RSI, 40(54.05\%) patients received premedications without statistically significant difference between the emergency physicians and anesthetists $(\mathrm{p}=0.145)$.

Out of 90 intubations, 73(81.11\%) intubations were successful in the first attempt. We compared the success rates of the first attempt (Figure 3) in performing endotracheal intubation among emergency physicians and anesthetists. Out of 70 endotracheal intubations performed by emergency physicians, $61(87.14 \%)$ were successful the first time.

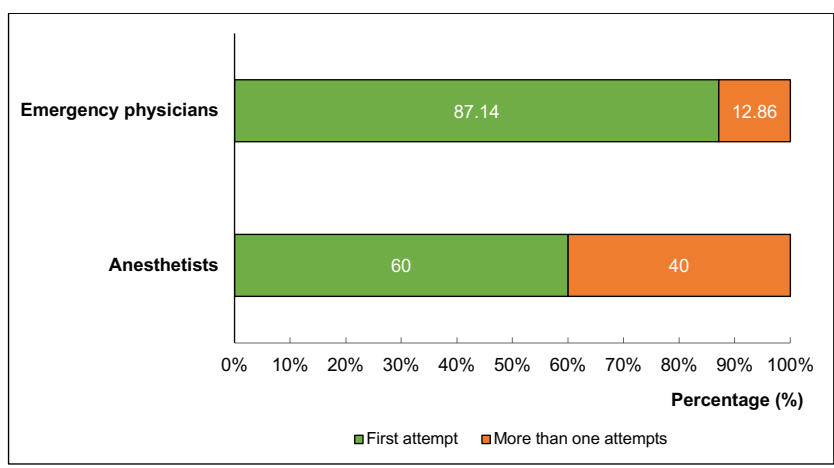

Figure 3. Showing the success of endotracheal intubation in the first attempt among emergency physicians and anesthetists.
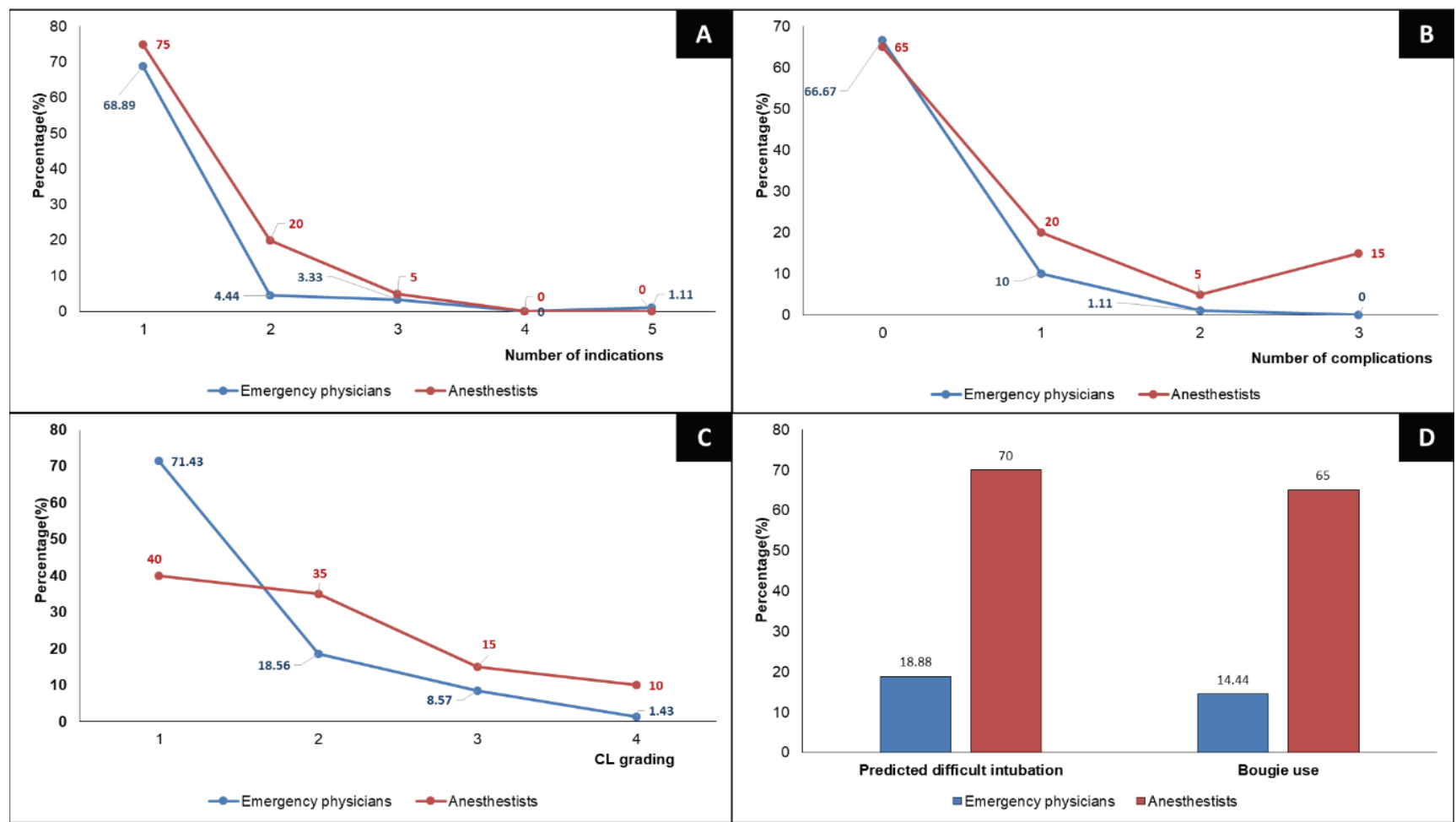

Figure 2: A) showing the number of indications and complications; B) showing the number of complications; C) showing CL grading, and D) showing predicted difficult intubation and bougie use among the two specialties. 
Among anesthetists, $12(60 \%)$ out of 20 intubations were successful in their first attempt. The differences were statistically significant. ( $p$ value $=0.003, \chi 2=7.48$ ). There was also a significant association between the 1 st attempt success rate and bougie use $(\chi 2=5.902 ; p=0.007)$.

Out of 90 patients, 73(81.11\%) did not develop any complications. Among the $17(18.89 \%)$ patients who developed complications, ten intubations were performed by emergency physicians, and the remaining seven by anesthetists with statistically significant differences $(\chi 2=$ 4.357, $\mathrm{p}=0.0184)$. Among the $17(18.89 \%)$ patients who developed complications, $13(14.44 \%)$ patients had one complication. In our study, two patients $(2.22 \%)$ had two complications each, and another two (2.22\%) developed three complications.). A total of 23 complications occurred in the patients, of which 11 occurred in patients intubated by the emergency physician and 12 occurred in patients intubated by the anesthetists. The differences between them were statistically significant $(\chi 2=16.04, p<0.001)$. The number of attempts was associated with an increasing number of complications (Pearson's correlation $=0.0550$ ). However, more than one indication for intubation was not associated with the number of complications (Pearson's correlation $=0.499)$. Desaturation $(n=10,11 \%)$ was the most commonly observed complication with a statistically significant difference between the emergency physicians and anesthetists. $(\chi 2=5.02 ; p=0.012)$. Figure 4 shows the prevalence of complications among the study patients. Bradycardia $(\chi 2=3.53 ; \mathrm{p}=0.029)$ and dental trauma $(\chi 2=$ 6.992; $\mathrm{p}=0.004)$ also had significant differences between the two departments.

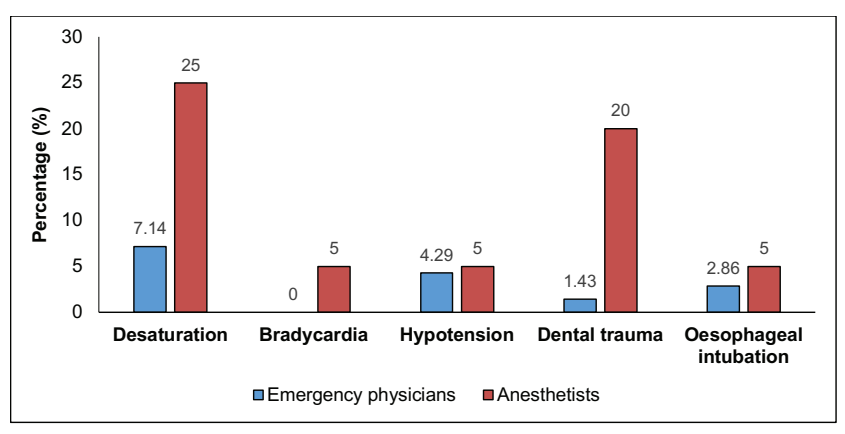

Figure 4. showing the prevalence of complications among the study patients.

\section{Discussion}

Through this cross-sectional study, we conducted a clinical audit to analyze the characteristics of $60(67 \%)$ males and 30 $(33 \%)$ females who were intubated over ten months in the emergency department of our teaching hospital. The majority of our patients $(n=59,65.5 \%)$ belonged to the age group of 55 to 75 years with a mean age of 61.2 years. The mean age group and the sex ratio were comparable with other studies in the literature $[8,12]$. Emergency physicians intubated more patients $(n=70,77.8 \%)$ because all the endotracheal intubations in the emergency department during the day (09.00-21.00) were performed by them. Anesthetists, on the other hand, performed endotracheal intubations in the operation theatre complex during the daytime. So, only 20 $(22.2 \%)$ intubations that were performed by anesthetists in the nighttime, while the emergency physician was unavailable in the emergency department, were included in our study.

A study of the practice of endotracheal intubation from a Scottish district hospital in 2007 [1] had shown comparable intubation rates between Emergency Physicians( 46\%) and Anesthetists (54\%). An airway audit conducted in the ED of a tertiary care hospital in Sydney ${ }^{8}$, Australia, revealed that emergency physicians did only $12.6 \%$ of all Emergency intubations, and the study expressed concerns of skill fade for the emergency physicians of their Department. Another study by Ron M Walls[13], which looked at 8937 intubations across 31 EDs across the US in 2010, published in JEM, recorded $87 \%$ intubations to be done by emergency physicians., while a more recently published study in 2015[14] which audited 3738 intubations done over 11 years in an urban ED of Scotland reveals that Emergency physicians do $78 \%$ of all intubations in the Emergency Department. Another recent study [15] from the London North West University Healthcare NHS. Trust, United kingdom depicted that emergency physicians performed only $11 \%$ of all intubations in the Emergency Department while the intensive care physicians did most of them (70\%).

Even though anesthetists intubated few patients $(n=20,22.22 \%$ vs. $70(77.78 \%)$ compared to the emergency physicians, there was no statistically significant difference $(p=0.063)$ in the number of indications the patients had for intubation. Respiratory failure $(n=25,27.78 \%)$ and intracranial haemorrhage/ stroke $(n=21,23.3 \%)$ were the most common indications in our study setting. Most patients $(\mathrm{N}=65,72.22 \%)$ were pre oxygenated with a bag-valvemask (BVM). Only one patient required CPAP/BiPAP as a preoxygenation modality. The indication was respiratory failure, and preoxygenation was attempted with CPAP initially. Still, as the patient did not achieve the desired oxygen saturation, the anesthetist changed the settings to provide BiPAP ventilation before intubating the patient.

To the best of our knowledge, this is the first study from southern India that described the practice of endotracheal intubation in the emergency department. A study done by Pradip Jadav[7]. on endotracheal intubation in the emergency department is the only report from India published before our research. This study included 114 study patients. They observed a higher number of complications $(n=38,33.3 \%)$ despite the frequent use of the bougie $(n=70$, $61.4 \%$ ) for the intubation process. They had zero percent adherence to the RSI technique. We found some interesting observations in drug preference among the two specialties. We used 12 drugs for intubation in our study setting, among which we found five drugs that had statistically significant differences in use between the specialties (Table 3). Among the drugs used for premedication, all 13(16.04\%) patients 
who received lignocaine $20 \%+$ fentanyl, were intubated by emergency physicians, and glycopyrrolate $(n=2,10 \%)$ was used exclusively by the anesthetists. Among relaxants, all eight patients $(9.88 \%)$ who received rocuronium were intubated by emergency physicians.

Both the specialties used LEON criteria to predict difficult intubation. We observed a statistically significant association between anticipated difficult intubation and bougie use $(\chi 2=6.09, \mathrm{p}=0.006)$. Anesthetists expected $14(70 \%)$ intubations to be difficult. $13(65 \%)$ patients required bougie for intubation. However, emergency physicians predicted $17(24.28 \%$ ) intubations to be difficult, among which bougie was used in $13(18.57 \%)$ patients.

In our emergency department, the first attempt success rate was $81.11 \%(n=73)$, with a significant difference between both departments. ( $p$ value $=0.003, \chi 2=7.48)$. There was a significant association between the number of attempts and an increasing number of complications (Pearson's correlation $=0.055)$. We also found a significant difference in RSI $(n=74 / 90)$ performed between the emergency physicians 59(79.73\%) and anesthetists 15(20.27\%) (Yates corrected chi square $=6.46 ; p=0.0013)$. Only $17(18.89 \%)$ patients in our study group developed complications. There was a significant difference between the two specialties $(\chi 2=$ 16.04, $\mathrm{p}<0.001)$. Among the complication, we observed desaturation $(\chi 2=5.02 ; \mathrm{p}=0.012)$, bradycardia $(\chi 2=3.53$; $\mathrm{p}=0.029)$ and dental trauma $(\chi 2=6.992, \mathrm{p}=0.004, \mathrm{p}=0.004)$ had statistically significant difference between the two specialities while hypotension was comparable across the specialties . Our data was comparable to Stevenson et al. ${ }^{1}$ from Scotland, who observed that desaturation was more for anesthetists who performed intubations while hypotension was comparable across the emergency physicians and anesthetists.

The indications (medical versus traumatic), firstpass success rates, complications which we obtained are compared with similar studies done in the western countries (Table 4). We achieved first attempt success rates comparable to the western studies. Though the overall complication rates were higher, we observed similar rates of hypotension and esophageal intubation among the study patients in our study.
Perhaps, one of the main limitations of our study was that the number of intubations performed by emergency physicians and anesthetises was not comparable. Thus, the findings comparing the two specialties should be interpreted with caution. Lesser first attempt success rate and high prevalence of complications among the anesthetises might be due to multiple reasons. RSI was performed significantly more by emergency physicians. A higher percentage of patients intubated by anesthetists had recorded CL grades of more than 2. Furthermore, the emergency physicians intubated all nine patients who had a cardiac arrest (both trauma and medical). These would have influenced the first attempt success rates and complications in our study.

\section{Conclusions:}

Our study demonstrated high first attempt success rates, which were comparable to other studies in the literature. Though the overall complication rates were higher, complications like hypotension and oesophageal intubation were similar to other studies. Ideally, a prospective study would have been better to compare the efficiency between the emergency physicians and anesthetists. Finally, we recommend that future prospective studies be conducted, including resident performed intubations to evaluate the airway managerial skills and training of emergency medicine residents to identify any lacunae in the same and ensure that no one dies in the emergency department for want of effective airway management.

COI Statement: This paper has not been submitted in parallel. It has not been presented fully or partially at a meeting or podium or congress. It has not been published nor submitted for consideration beforehand.

Acknowledgement: Author acknowledge Dr. Ramiz for helping with statistical analysis. We also thank Dr. Andrew Thomas for writing and editing the final manuscript for our study.

Funding: This research did not receive any specific grant from funding agencies in the public, commercial, or not-for-profit sectors.

Conflicts of interest: Author declared no conflict of interest. No funding was received for this study.

Table 4. comparing indication, first attempt success rates, and complications with other studies.

\begin{tabular}{|l|l|l|l|l|l|l|l|}
\hline & $\begin{array}{l}\text { Indications } \\
\text { (Medical/ Trauma) }\end{array}$ & $\begin{array}{l}\text { First Pass } \\
\text { Success Rate }\end{array}$ & $\begin{array}{l}\text { Complications } \\
\text { (Overall) }\end{array}$ & Hypotension & Desaturation & $\begin{array}{l}\text { Oesophageal } \\
\text { Intubation }\end{array}$ & $\begin{array}{l}\text { RSI. } \\
\text { Adherence }\end{array}$ \\
\hline Current study & $\mathbf{8 8 / 3 2}$ & $\mathbf{8 1 . 1}$ & $\mathbf{1 8 . 9}$ & $\mathbf{4 . 4}$ & $\mathbf{1 1}$ & $\mathbf{3 . 3}$ & $\mathbf{8 2 . 2}$ \\
\hline Kerslake et al (2015).[13] & $77 / 23$ & 85 & 8 & 4.5 & 1.7 & 2.7 & 74 \\
\hline Stevenson et al (2011)[1] & $62 / 38$ & 87 & 21 & 12 & 11 & 3 & 85 \\
\hline Walls et al (2011).[12] & $67 / 26$ & 95 & 12 & 1 & NR & 3 & 69 \\
\hline Fogg et al (2012).[13] & $69.5 / 30.5$ & 83.4 & 28.5 & 4 & 15.7 & 4 & NR \\
\hline Fadhlillah[14] et al (2020) & NR & 32.9 & 8.5 & 3.2 & 2.1 & NR & NR \\
\hline
\end{tabular}




\section{References:}

1. Stevenson A.G.M., Graham CA, Hall R, Korsah P, McGuffie AC. Tracheal intubation in the emergency department: The Scottish district hospital perspective. Emerg Med J. 2007;24(6):394-7. DOI: 10.1136/ emj.2006.041988.

2. Ono Y, Kakamu T, Kikuchi H, Mori Y, Watanabe Y, Shinohara K. Expert-Performed Endotracheal Intubation-Related Complications in Trauma Patients: Incidence, Possible Risk Factors, and Outcomes in the Prehospital Setting and Emergency Department. Emerg Med Int. 2018;2018:1-9. DOI: 10.1155/2018/5649476.

3. Medical Council of India (MCI). Medical Council of India Notification. New Delhi: The Gazette of India: Extraordinary; 2009 p. 12.

4. Adams M, Bandara L. Airway management in the emergency department. Br J Anaesth. 2002;88(6). DOI: $10.1093 / \mathrm{BJA} / 88.1 .9$

5. Wright KD, Cadamy AJ, White M, Walker A, Brenchley J. Survey of the use of rapid sequence induction in the accident and emergency department (multiple letters). Emerg Med J. 2001;18(3):232-3. DOI: 10.1136/ emj.17.2.95

6. Fathil SM, Mahdi S.N.M., Che'Man Z, Hassan A, Ahmad Z, Ismail AK. A prospective study of tracheal intubation in an academic emergency department in Malaysia. Int J Emerg Med. 2010;3(4):233-7.

7. Dr. Pradip Jadav Study of Endotracheal Intubation in Emergency Room of a Tertiary Care Hospital of Ahmedabad City of Gujarat, India International Journal of Scientific Research, Vol.II, Issue.XII December 2013. DOI: $10.1007 / \mathrm{s} 12245-010-0201-0$

8. Fogg T, Annesley N, Hitos K, Vassiliadis J. Prospective observational study of the practice of endotracheal intubation in the emergency department of a tertiary hospital in Sydney, Australia. Emerg Med Australas. 2012 Dec;24(6):617-24. DOI: 10.1111/17426723.12005 .
9. Reed MJ, Dunn MJ, McKeown DW. Can an airway assessment score predict difficulty at intubation in the emergency department? Emerg Med J. 2005 Feb;22(2):99-102. DOI: 10.1136/emj.2003.008771.

10. Krage R, van Rijn C, van Groeningen D, Loer SA, Schwarte LA, Schober P. Cormack-Lehane classification revisited. Br J Anaesth. 2010 Aug;105(2):220-7. DOI: 10.1093/BJA/aeq136. Epub 2010 June 16.

11. Hockberger, R, Gausche-hill, M. Rosen's Emergency Medicine: Concepts and Clinical Practice. (9th ed.). United States: Elsevier; 2017.

12. Fogg T, Alkhouri H, Vassiliadis J. The Royal North Shore Hospital Emergency Department airway registry: Closing the audit loop. Emerg Med Australas. 2016 Feb;28(1):27-33. DOI: 10.1111/1742-6723.12496. Epub 2015 November 11. DOI: 10.1111/17426723.12496.

13. Walls RM, Brown CA 3rd, Bair AE, Pallin DJ; NEAR II Investigators. Emergency airway management: a multi-center report of 8937 emergency department intubations. J Emerg Med. 2011 Oct;41(4):347-54. DOI: 10.1016/j.jemermed.2010.02.024.

14. Kerslake D, Oglesby AJ, Di Rollo N, James E, McKeown DW, Ray DC; EDIR investigators. Tracheal intubation in an urban emergency department in Scotland: a prospective, observational study of 3738 intubations. Resuscitation. 2015 Apr;89:20-4. DOI: 10.1016/j.resuscitation.2015.01.005.

15. Fadhlillah F, Bury S, Grocholski E, Dean M, Refson A. Emergency Airway Management: A Look into the Practice, Rate of Success, and Adverse Events of 94 Endotracheal Intubations. J Emerg Trauma Shock. 2020 Jan-Mar;13(1):58-61. DOI: 10.4103/JETS JETS_100_19. 